


\title{
Centimeter
}

$\begin{array}{llllllllllllllll}1 & 2 & 3 & 4 & 5 & 6 & 7 & 8 & 9 & 10 & 11 & 12 & 13 & 14 & 15 & \mathrm{~mm}\end{array}$



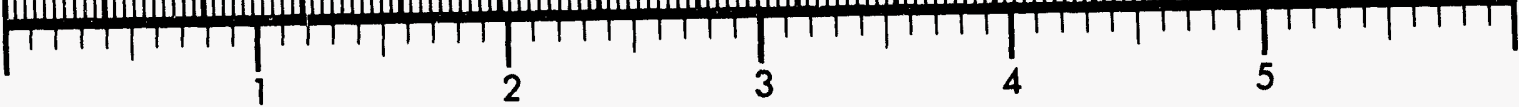
Inches
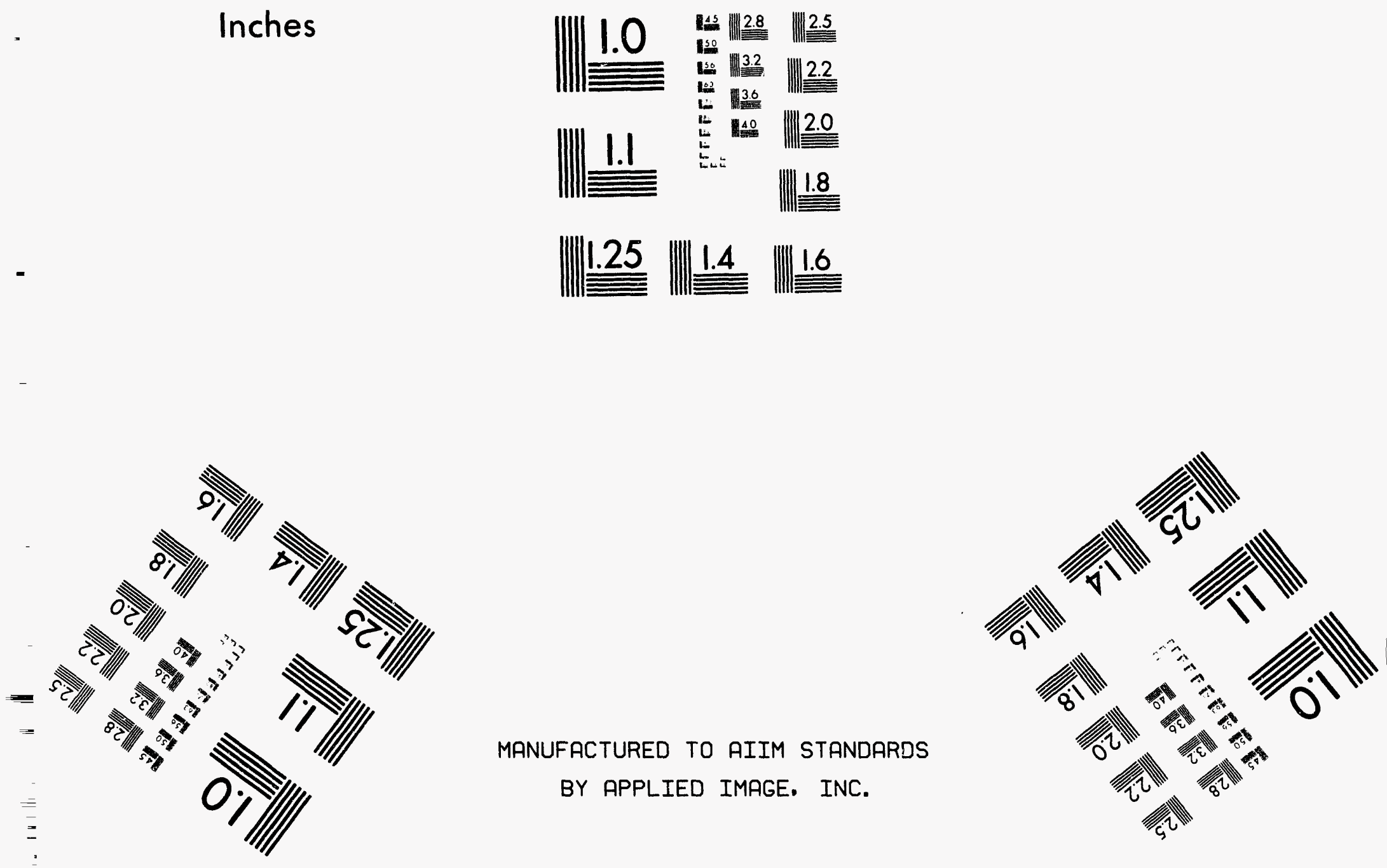

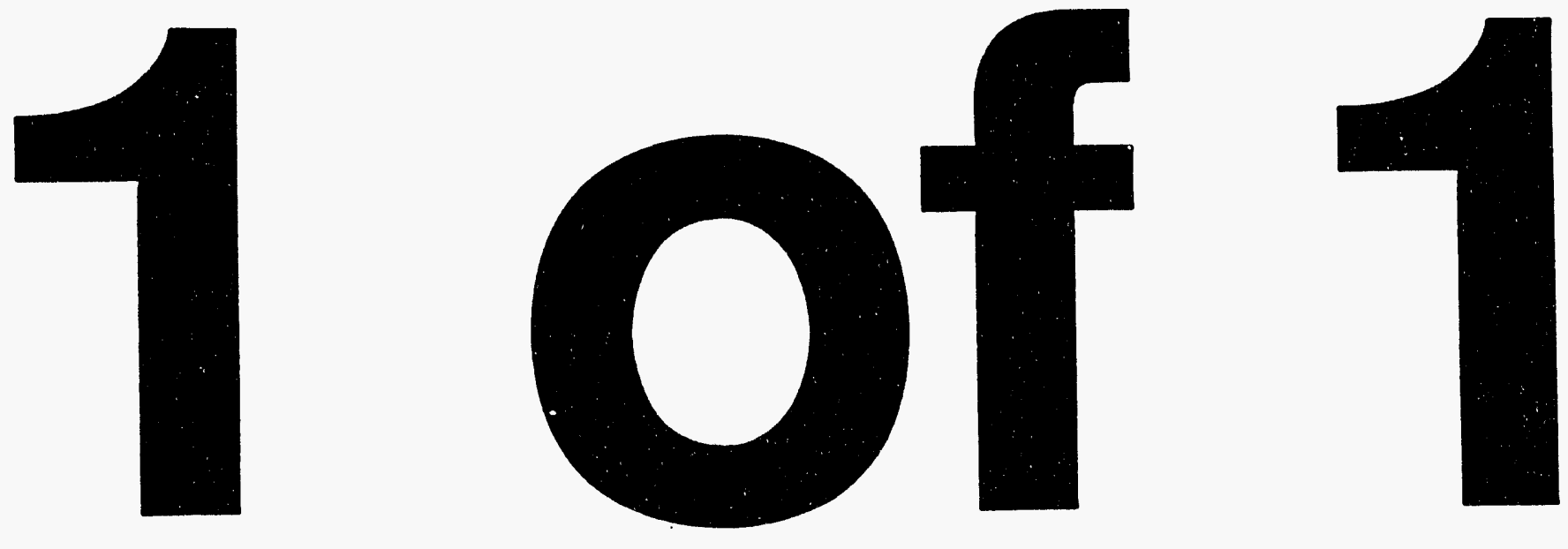


\section{conf-9410131--5 \\ Experimental Hypervelocity Impact Effects \\ On \\ Simulated Planetesimal Materials}

William J. Tedeschi

Sandia National Laboratories

Albuquerque, NM USA

James F. Schulze

Sandia National Laboratories

Albuquerque, NM USA by

\author{
John L. Remo \\ Quantametrics, Inc. \\ St. James, NY USA
}

Raymond P. Young, Jr.

Calspan Corp./AEDC

Arnold AFB, TN USA

\section{DISCLAIMER}

This report was prepared as an account of work sponsored by an agency of the United States Government. Neither the United States Government nor any agency thereof, nor any of their employees, makes any warranty, express or implied, or assumes any legal liability or responsibility for the accuracy, completeness, or usefulness of any information, apparatus, product, or process disclosed, or represents that its use would not infringe privately owned rights. Reference herein to any specific commercial product, process, or service by trade name, trademark, manufacturer, or otherwise does not necessarily constitute or imply its endorsement, recommendation, or favoring by the United States Government or any agency thereof. The views and opinions of authors expressed herein do not necessarily state or reflect those of the United States Government or any agency thereof.

presented at the

1994 HyperVelocity Impact Symposium (HVIS)

Santa Fe, New Mexico USA

October 16-20, 1994 


\title{
Experimental Hypervelocity Impact Effects On Simulated Planetesimal Materials
}

\author{
William J. Tedeschi \\ Sandia National Laboratories \\ Albuquerque, NM USA \\ James F. Schulze \\ Sandia National Laboratories \\ Albuquerque, NM USA
}

by
John L. Remo
Quantametrics, Inc.
St. James, NY USA
Raymond P. Young, Jr.
Calspan/AEDC Operations
Arnold AFB, TN USA

\begin{abstract}
Experimental results are presented from a series of hypervelocity impact tests on simulated comet and asteroid materials for the purpose of characterizing their response to hypervelocity kinetic energy impacts. Nine tests were conducted at the Air Force Arnold Engineering Development Center (AEDC) S1 Range Facility on ice, rock, and iron target samples using a spherical $2.39 \mathrm{~mm}$ diameter aluminum impactor at impact velocities of from 7.6 to $8.4 \mathrm{~km} / \mathrm{sec}$. The test objectives were to collect target response phenomenology data on cratering, momentum deposition and enhancement, target fragmentation, and material response under hypervelocity impact loading conditions. A carefully designed ballistic pendulum was used to measure momentum deposition into the targets. Observations and measurements of the impacted samples provide important insights into the response of these materials to kinetic energy impacts, especially in regards to unexpectedly large measured values of momentum enhancement to some of the targets. Such information is required to allow us to successfully ceflect or fragment comets or asteroids which might someday be detected on collision trajectories with Earth.
\end{abstract}




\section{Introduction}

Compelling evidence of a catastrophic asteroid impact on the Earth 65 million years ago $[1,2]$ has given rise to international discussions about the probability and prevention of future impacts. As a result of several recent near-misses $[3,4]$, considerable international attention has focused on defining the impact threat and determining potential mitigation schemes for the protection of Earth against planetesimal impacts [5]. Initial studies indicate that hypervelocity impact is one of several favorable schemes for mitigating the possibility of Earth-impact by such bodies [6]. A desirable characteristic for a defensive engagement would be to deflect the approaching body into a new, non-threatening trajectory by momentum transfer or deposition. However, fragmenting the body into numerous pieces might make the problem worse, since some of the resultant debris could still be on an Earthcrossing trajectory. While there are some data on the fragmentation of planetesimal-type materials, e.g., basaltic rocks [7] and ice [8], nowhere have we found experimental data on momentum deposition into such materials due to hypervelocity kinetic energy impacts. Simulating the macroscopic change in momentum of such bodies is difficult to do using modern shock-physics computational codes, e.g., hydrocodes, mainly due to inherent numerical limitations [9]. Therefore, a critical need exists to obtain well-characterized hypervelocity impact test data on actual Near-Earth-Object (NEO) materials or NEO material analogs for code calibration purposes.

The scientific endeavors associated with geophysical planetary evolution also benefit directly from this type of impact test series. Hypervelocity impact interactions and their related catastrophic effects have traditionally been invoked as the major plausible mechanism that determines the mass spectra and velocity dispersions during planetary accretion and fragmentation [10]. Modeling such 
impact interactions can be very complicated, especially when either the target or impactor are composed of natural materials which in many cases are inhomogeneous assemblages of minerals with faults, inclusions, grain and phase boundaries, and other imperfections which complicate the material response. The response of such materials to hypervelocity impact spans a wide range of material behavior, ranging from high impact temperatures and pressures, where hydrodynamic motion and thermodynamic effects predominate, to the low pressure regions where the mechanical properties dominate the process. In order to simulate such processes using sophisticated computer models it becomes necessary to understand the fragmentation effects of hypervelocity impact on related inhomogeneous targets through experimentation over a range of loading conditions, velocities, and target and projectile materials. Results from such experiments can then be used to test and validate computer models for the simulation of planetary interaction processes.

\section{Objectives}

The test series objectives were to generate, interpret, and ultimately model data related to the response of comet and asteroid analog materials to hypervelocity kinetic energy impacts. Specifically, the following aspects of the problem include:

1. Momentum deposition: The amount of momentum coupled into the target body as a result of the impact. Of particular interest is momentum enhancement due to impactor/target energy coupling and partitioning causing ejected target material to contribute additional momentum coupling into the target.

2. Crater morphology: Penetration depth, crater diameter and shape, material excavation, and other possible effects elsewhere on the body, such as plastic deformation and far-side spallation. 
3. Fragmentation: Fragmentation threshold as a function of impactor energy and target material and structure, and cumulative fragment size distributions.

4. Constitutive material response: Effect of target body shape and material inhomogeneities, e.g., grain boundaries and inclusions, on target response. A key element will be to examine the effect of material porosity on the observed cratering, crater melt lining due to highly adiabatic shocked material interfaces, momentum transfer, and fragmentation data.

\section{Impact Test Facility}

The Air Force AEDC S1 range hypervelocity light-gas gun consists of a launcher mount, blast chamber, three target tanks, and a vacuum pumping system (see Fig. 1). Launchers available for use in the S1 facility include two-stage light-gas guns, approximately $6 \mathrm{~m}$ long, having bore diameters of 8.4, 12.7, and $15.9 \mathrm{~mm}$. The launcher extends into the up-range end of the blast chamber which is used to diffuse the gun's muzzle blast and separate the sabot from the projectile. For this test series, the S1 facility and standard method of operation were modified to duplicate the 8.4 $\mathrm{mm}$ launcher installation used in the AEDC Range/Track G for a "counter-fire" test effort, a new test technique described below. The sabots were aerodynamically separated in an air environment at an ambient pressure of 10 torr $(0.001 \mathrm{~atm})$, and allowed to impact a sabot stripper, a steel plate with a $2.54 \mathrm{~cm}$ diameter hole on the shot line. The sabot stripper was placed at the up-range end of the intermediate target chamber $7.5 \mathrm{~m}$ from the launcher muzzle. A small target chamber, $30.5 \mathrm{~cm}$ in diameter, was installed in the connecting tube between the intermediate and second target chambers $14.3 \mathrm{~m}$ from the launcher muzzle. A more complete description of the facility is contained in [11]. 
The impact tests were conducted during the $8.4 \mathrm{~mm}$ launcher calibration phase of the AEDC counter-fire demonstration program. The counter-fire technique was developed to provide impacts at extremely high relative velocities, approaching 16 $\mathrm{km} / \mathrm{sec}$. The high velocities result from the intercept of two projectiles launched nearly simultaneously from opposing, two-stage light-gas guns. The target projectile is launched from the Range/Track G $84 \mathrm{~mm}$ gun at velocities ranging from 2-7 $\mathrm{km} / \mathrm{sec}$. The target travels along a track to the impact location, where it is intercepted by a projectile traveling at up to $8.5 \mathrm{~km} / \mathrm{sec}$ launched from the opposing $8.4 \mathrm{~mm}$ diameter gun. The impacted "target" then enters a recovery system for retrieval and post-test analysis. The counterfire technique can provide impact data on a number of different targets, including reentry vehicles, shuttle windows or tiles, debris shields, or satellite components. Targets containing small amounts of hazardous materials can also be tested, such as hypergolic fuels or high explosives. The impactor can be of different shapes and materials, but is limited by the launcher diameter of $8.4 \mathrm{~mm}$. Multiple projectiles, simulating a debris field or fragmentation warhead, can also be launched. more realistically

Instrumentation

Active instrumentation operated during the test series included two $X$-ray shadowgraph systems and one silicon photodiode radiometer. The X-ray stations were located in the blast chamber along the flight path of the projectile. The X-ray shadowgraph data obtained were used to measure projectile velocity and monitor sabot separation. The silicon photodiode, which viewed the target in a direction orthogonal to the shot-line, was operated unfiltered with a spectral response range of approximately 0.4 to 1.1 micrors. Information obtained by the radiometers includes projectile arrival time, and impact flash intensity and duration. Passive instrumentation consisted of the ballistic pendulum which recorded the maximum angular deflection of the target material due to the projectile impact. 


\section{Ballistic Pendulum and Momentum Enhancement}

A light-weight ballistic pendulum was designed, fabricated, and qualified to passively measure the level of momentum deposition to each target due to the projectile impact. The net deposited target momentum consists of two components: the momentum of the impacting projectile and a momentum enhancement from the impact ejecta, i.e., mainly target material being projected outward from the target with a resultant momentum gain to the target. Momentum enhancement is given here as

Momentum enhancement $=$ impactor momentum + ejecta momentum gain $=$ measured target momentum impactor momentum impactor momentum

Considering a global conservation of momentum constraint, momentum enhancement can be defined more rigorously as

$$
\text { Momentum Enhancement }=\frac{p_{i}+a b s\left(\sum_{k=1}^{N} p_{k} \cdot n\right)}{p_{i}}
$$

where: $\quad p_{i}=$ Impactor momentum vector

$\mathrm{p}_{\mathrm{k}}=\mathrm{kth}$ ejecta debris (solid, liquid, vapor, or plasma) momentum vector

$\mathbf{n}=$ target surface outward normal vector, coincident with the impactor's velocity vector

$\mathrm{k}=1$ to $\mathrm{N}$

$N$ = total number of ejecta debris projected outward from the target

A simple ballistic pendulum was the measurement device of choice for measuring momentum enhancement because of its low cost, simplicity, and ease of use. Other researchers have used various momentum deposition measurements devices and techniques $[12,13]$, some direct and others indirect in approach, to measure debris 
fields and induced momentum in impacted targets, with varying levels of success and precision. A key contribution in the present effort is that great care was taken to design and calibrate as accurate a ballistic pendulum as possible.

Using a modified version of the standard ballistic pendulum equation [14], the derived target momentum is given here as a function of the final target mass, the pendulum arm length, and the measured maximum angular deflection:

$$
\text { target momentum }=\left[2 \mathrm{mtf}^{2} \mathrm{~g} \mathrm{~L}(1-\cos ø)\right]^{1 / 2}
$$

$$
\text { where: } \begin{aligned}
\mathrm{m}_{\mathrm{tf}} & =\text { final target mass, measured in } \mathrm{gm} \\
\mathrm{g} & =\text { gravitational constant, } 9.8 \mathrm{~m} / \mathrm{s} \\
\mathrm{L} & =\text { ballistic pendulum arm length, } 12.0 \mathrm{~cm} \\
& =\begin{array}{c}
\text { maximum ballistic pendulum angular } \\
\text { displacement, measured in degrees }
\end{array}
\end{aligned}
$$

The ballistic pendulum (see Fig. 2) consisted of a plastic pan-shaped target holder or cup (weighing only 28.3 grams), a steel suspension pin, two low-friction ball bearings, an outer bearing assembly, a protractor - to measure angular deflection, a one-way angular displacement arm, and a blast chamber interface attachment. The angular displacement arm had a small amount of vacuum grease placed on the circular rim which mated with the outer bearing assembly for the purpose of holding the arm at the position of maximum deflection after the impact. Of course, the induced pendulum oscillations damp out over time with monotonically decreasing angular maxima, thus allowing the maximum angular deflection to be captured by this technique. Also, a cylindrical steel cup, $50 \mathrm{~mm}$ deep by $54.8 \mathrm{~mm}$ in 
diameter and which was mounted in a hole in one of the target cups, was used to hold the ice samples.

A number of considerations were factored in during the design phase. The momentum measuring device had to be passive in nature and had to hold the recorded angular displacement value over a period of time while the ejecta debris field dissipated and the blast chamber pressure was raised back to one atmosphere. Thought was given to the use of passive intact-capture, or soft-catch, materials [12], but these were ruled out due to the need for careful calibration of such materials. A big unknown in the pendulum design phase was the dynamic range in maximum angular deflection which could be expected for the broad range of targets and resultant responses, especially that of momentum enhancement which could only be estimated at beforehand to be from between 1 and 2 in value. Provision was therefore made to allow the addition of thin circular disks of high-density Tungsten as ballast weights to reduce the dynamic range of the pendulum if required.

The response of the ballistic pendulum was characterized and qualified in two ways. In the first case, angular deflection calibration shots were conducted at a pistol range using two types of low-mass, low-velocity .22-caliber bullet slugs. A cylinder of soft wood was placed inside the steel ice cup assembly to inelastically capture the .22 slug of known momentum, thereby allowing us to assume that the incoming slug momentum equals the imparted momentum to the pendulum target. A chronograph instrument was used to measure accurately the slug's impact velocity. The derived target momentum using the measured deflection angle was calculated using the ballistic pendulum equation above. Table 1 shows the results of these calibration tests. The resulting accuracy on derived target momentum was measured to be within about $+/-10 \%$ of the known imparted target momentum. 
Also, frictional losses in the bearings were found to be negligible by simple proof tests whereby the pendulum target was raised to various deflection angles, up to 55 degrees, and then released. The pendulum swung down and then up on the opposite side to within 1 degree (the reading accuracy of the protractor) of the initial deflection angle.

\section{Test Set-Up and Procedure}

The target materials were mounted in the ballistic pendulum cup using $0.47 \mathrm{~g} / \mathrm{cm}^{3}$ polyurethane foam and attached inside the target impact chamber (see Fig. 3). After each test, before the target chamber was re-pressurized and entered, the ballistic pendulum's angular displacement arm was read through a clear plexiglas end-cap window in the target impact chamber. The impact flash radiometer was oriented toward the target through this window. After re-pressurization, the target was removed and target fragments were picked up off the floor if fragmentation had occurred. In the case of the cold targets, the ice targets were cooled in liquid Nitrogen (LN) at $-196^{\circ}$ Celsius for one hour beforehand. The target temperature appeared fully equilibrated. At the latest possible moment, once the gun powder chamber and pump tube were pressurized and just before the blast and impact chamier de-pressurization process, the cold target was removed from the LN and mounted in the impact chamber. No melting of the frozen ice material was noted afterward when the samples were recovered - a total elapsed time of about 20 minutes after removal from the LN. The impact chamber was then cleaned and readied for another shot.

\section{Impact Targets}

Some NEOs, or more appropriately near-Earth asteroids, appear to, at least superficially, resemble certain classes of meteorites [15]. This resemblance derives from what appears to be a correlation between terrestrially recovered meteorite specimens and the reflectance spectra from main-belt asteroids. This association is 
becoming more apparent as additional observational results accrue [15]. However, all NEOs may not be derived from asteroid-like bodies; some NEOs are thought to be composed of material from devolitized, dormant, or extinct comets. Comets pose a particularly difficult problem regarding target selection since there is no appreciable amount of comet material on Earth with which to make such targets. At best, from our knowledge of comet spectra, cosmic dust samples, and recent results from the Giotto and Vega missions, we could only infer some of the material properties of comet nuclei [16].

The selection of the NEO analog target materials in these tests were derived from terrestrial mineral specimens which resemble the minerals found in the differentiated meteorites and, by extension from the above arguments, are assumed to be abundant in NEOs. The target materials selected are given as:

1. Magnesium/iron (olivine) silicate rocks: One was an olivine bomb, from Kilgore, New Mexico, composed of sub-millimeter to millimeter sized olivine crystals tightly bound in an inclusion-rich silicate media. The other specimen was an iron-rich olivine rock from the Laramie Range, Wyoming.

2. Scoraceous rock: With a porosity of approximately $10 \%$.

3. Comet Analog: A frozen, cylindrical-shaped compacted mixture of snow, silica dust, and carbon powder of overall dimensions $50 \mathrm{~mm}$ long by $54.8 \mathrm{~mm}$ in diameter. The composition by mass percentages was approximately $70 \%$ fluffy snow, 28\% silica powder (dried Nyacol colloidal silica powder 0.1 microns in diameter), and $2 \%$ carbon (fine graphite powder). The target was stored in a refrigerator at -10 degrees $C$ and cooled to $L N$ temperature just before the test. 
4. Compacted Snow: A frozen, cylindrical-shaped chunk of compacted fluffy snow of dimensions $50 \mathrm{~mm}$ long by $54.8 \mathrm{~mm}$ in diameter. The target was also stored in a refrigerator and cooled to the temperature of $\mathrm{LN}$ before the test.

5. Ice: A frozen, cylindrical-shaped ice chunk of dimensions $50 \mathrm{~mm}$ long by $54.8 \mathrm{~mm}$ in diameter and cooled to the temperature of $\mathrm{LN}$ before the test.

6. Nickel-Iron Metecrite: A coarse octahedrite iron meteorite specimen from the Ector County (Odessa), Texas fall, containing approximately $10 \%$ nickel. It contained some small olivine crystals and circular troilite inclusions.

7. Andesine-basalt rock: From Holterkollen, Nitterdal Norway containing inclusions of andesine chondrites ranging in size from a few millimeters to $20 \mathrm{~mm}$.

8. Aerogel: A commercially available (called Airglas ${ }^{T M}$ ), low-density $(0.224$ $\mathrm{g} / \mathrm{cm}^{3}$ ), very-high-porosity silica structure.

The measured target densities and initial masses are shown in Table 2. Since there is still some uncertainty with respect to the structure and composition of comets, our impact experiments may have limited applicability. We suspect that comet densities are less than $1 \mathrm{~g} / \mathrm{cm}^{3}$ and have a structure corresponding to amorphous ice which possesses mechanical and thermal properties considerably different from terrestrially encountered ice. Even if the recently constructed model of Greenberg and Remo [16] is correct, it may be very difficult to reconstruct this exact microstructure on a large scale. Nonetheless, we can distinguish between the mechanical properties of pure water (ice) and various silica rich colloids of water 
with admixtures of hydrocarbons, elemental carbon, and ferro-magnesium silicates. Also, by varying the density and porosity, the effects of this parameter on penetration depth, fragmentation spectra, crater morphology, spallation, and overall structural integrity can be analyzed. If the orbits of comets are to be changed by mechanical means, i.e., by hypervelocity impact, extensive and detailed research on the material structure must be carried out to determine the limits of possible comet mechanical and thermal response. This uncertainty underscores the need not only for this type research in analyzing analog NEO materials, but also for exploratory comet rendezvous missions.

Test Matrix

A total of nine hypervelocity impact tests were conducted on the AEDC S1 hypervelocity gun range. The impactor in each test was a spherical 1100 aluminum projectile of $2.39 \mathrm{~mm}$ diameter and $0.0192 \mathrm{gm}$ mass. The complete test matrix, which includes one calibration shot, is shown in Table 2. Table 3 shows the measured maximum ballistic pendulum deflection angle for each shot. Note that in 5 of the 9 shots, the pendulum pegged out at the maximum allowable deflection angle. It is clear that we underestimated the level of momentum deposition, i.e., the momentum enhancement effect, to the target materials.

The effect of muzzle blast on the performance of the ballistic pendulum was discovered to be of concern early in the test matrix. In one unrecorded test shot, the projectile impacted the sabot stripper plate well short of the target, but the muzzle blast - consisting of a jet of hydrogen gas trailing the projectile - continued downrange and interacted with the target. A small deflection angle was recorded by the pendulum. To remove this effect as a spurious target momentum deposition contribution, a thin blast shield composed of 2-mil $(0.0508 \mathrm{~mm})$ thick orthogonalweave Nylon fabric was placed about $40 \mathrm{~mm}$ in front of the target. Calibration shot 


\section{FINAL DRAFT}

540 (see Table 3) proved that the nylon blast shield stopped the muzzle blast from reaching the target, which in this case was a sheet of Mylar placed over the hole in the open ballistic pendulum cup.

The nylon blast shield was thin to the extent that the projectile passed through the nylon material with little effect and then impacted the target. A detailed twodimensional CTH hydrocode [17] calculation, with 20 computational cells through the projectile material and 5 through the nylon blast shield, verified this fact. The calculation indicates the projectile deformed somewhat, but was still intact by the nylon blast shield impact (see Fig. 4). Also, the residual projectile velocity was reduced to $7.95 \mathrm{~km} / \mathrm{s}$ versus an initial velocity of $8.0 \mathrm{~km} / \mathrm{s}$, a reduction of only $0.6 \%$, and there was no calculated mass loss. It should be noted that past efforts to measure momentum deposition using ballistic pendulum devices apparently did not address explicitly the effects of muzzle blast, nor did they indicate how the devices were calibrated. Shieids were also placed strategically around the ballistic pendulum to protect the angular displacement arm from any spurious ejecta debris effects and from indirect muzzle/impact blast.

\section{Analysis and Interpretation of Experimental Results}

The frozen ice targets in general experienced the largest momentum enhancements of from $>5.8$ to 9.7 , much higher values than had been anticipated based on our prior limited understanding of momentum enhancement in other types of hypervelocity impacts, e.g., in [18, 19]. We originally believed these large momentum enhancement values were due to the steel cup structure in which the ice targets were contained. Perhaps the open cup "channeled" the high pressure ejecta field back uprange, like a pulse jet, with a resultant equal but opposite force to the cup creating a momentum gain to the target. However, after further analysis we believe that hypervelocity impacts into volatile materials, like water, result in very 
energetic, momentum-enhancing, ejecta pulses due primarily to the large volumetric phase changes involved. Figure 5 shows comparison two-dimensional CTH [17] calculations of impacts into the confined ice target tested and into a quasi-semi-infinite ice target. To first order, the observed ejecta fields and crater growth characteristics are very similar, and that the presence of the cup doesn't have an appreciable effect on the hydrodynamics of the problem. The ice target was totally excavated except for a small pile of mm-sized ice ruble at the bottom of the steel cup. This result is somewhat consistent with published data on a temperate ice of impact strength $0.05 \mathrm{~J} / \mathrm{g}$ [8], versus the $6.0 \mathrm{~J} / \mathrm{g}$ specific impact energy in this test.

The measured crater dimensions in the two compressed snow targets, called comet analog and compacted snow, are shown in Fig. 6. Because these two targets had almost identical densities and somewhat similar crater dimensions, this suggests that the presence of silica dust and carbon powder did not grossly change the cratering result observed on the comet analog shot. It is probably because of the porosity of these two targets relative to the ice target that they did not totally fragment as did the ice target, even though the average specific impact energy was higher at about $9 \mathrm{~J} / \mathrm{g}$.

The low-density aerogel target also experienced a large momentum enhancement factor of $>4.76$. Its somewhat irregular crater dimensions are given in Fig. 7, but they are consistent with other hypervelocity impact results using such low density target materials [20]. It is believed, again, that the energetic silicate ejecta field contributed to the large momentum enhancement factor.

The derived momentum enhancement factor for the nickel-iron meteorite target was only 1.14 , more in line with expectations. However, this low value was due in 
part to the fact that the projectile impacted an oblique surface of the target, a slope 50 degrees away from a normal impact (see Fig. 8). Consequently, the ejecta was directed downward, nrimarily in a plane orthogonal to the initial projectile impact angle - as evidenced by an eroded section in the edge of the target cup. Had the projectile impacted a normal surface, as was originally intended but which was not achieved due to a slight amount of projectile flight dispersion, then the enhancement factor undoubtedly would have been greater. The measured crater dimensions are also given in Fig. 8, and a close-up photograph is shown in Fig. 9. Free surface spallation and in-depth radial fractures were observed up to 2 crater diameters away from the impact point. No other material response effects were observed elsewhere on the meteorite target.

Analysis of the rock shots, where large momentum enhancement factors of $>2.94$ to $>4.18$ were measured, shows some interesting contrasts. The impact on the scoraceous rock resulted in a relatively small, but highly irregular crater (see Fig. 10), even though the specific impact energy was the highest at $7.9 \mathrm{~J} / \mathrm{g}$. The olivine bomb and iron-rich olivine rocks catastrophically fragmented at the relatively low energy levels of 1.1 and $4.0 \mathrm{~J} / \mathrm{g}$. The andesine-basalt rock experienced some front- and backsurface spallation at a specific impact energy level of $1.1 \mathrm{~J} / \mathrm{g}$ (the impact crater was obliterated as a result). This is consistent with published results where the average body fragmentation threshold, or impact strength, is about $6.0 \mathrm{~J} / \mathrm{g}$ [7]. The scoraceous rock only cratered and did not fragment because of the relative impact strength of the rock (at least $7.9 \mathrm{~J} / \mathrm{g}$ ) and due to the random porosity of the mineralogical microstructure serving to rapidly attenuate transmission of the impact-generated shock wave due to impedance mismatches across irregular phase boundaries. On the other hand, the olivine rocks are composed of relatively weak structural materials and are relatively brittle in response to shock loading. The recovered 
olivine bomb fragments are shown in Fig. 11 and the measured cumulative fragment distribution is given in Fig. 12. Even though the recovered fragments account for only $45 \%$ of the total original target mass, the measured distributions are in good agreement (see Fig. 12) with two existing empirical fragment distribution powe.. law models $[21,22]$.

\section{Summary}

A nine-shot impact test series was conducted at the Air Force AEDC test facility whereby comet and asteroid analog materials were impacted by hypervelocity kinetic energy projectiles to provide hitherto unavailable data on momentum deposition characteristics for such materials. Information was presented about how these materials crater and fragment, as well as some insights on their previously undefined momentum enhancement characteristics. These data are vitally important both to the international community as a whole in providing mitigation options for defense of the Earth from catastrophic impacts by comets and asteroids, and to planetary scientists who desire to have a more extensive database from which to model planetesimal accretion and fragmentation dispersion processes, especially at velocities above $5 \mathrm{~km} / \mathrm{s}$. An original contribution was also made in the design, calibration, and use of a simple, low-cost, but effective, ballistic pendulum device.

\section{Acknowledgments}

This work was supported by the United States Department of Energy under contract DE-AC04-94AL85000. The authors wish to acknowledge the excellent technical support received from Carol Ashley, Eugene Hertel, David Ingersol, and Peter Truske, of Sandia National Laboratories.

\section{References:}

[1] Alvarez, L. W., Alvarez, W., Assaro, F., Michel, H.H., 1980, Extraterrestrial Cause for the Cretacous-Tertiary Mass Extinction, Science, Vol. 208, pp. 1095-1108. 
[2] Sharpton, V. L. and Ward, P.D., eds., 1990, Global Catastrophes in Earth History: An Interdisciplinary Conference on Impacts, Volcanism, and Mass Mortality, Geological Society of America, Special Paper 247, pp. 1-98, 417-606.

[3] Morrison, D., 1992, The Spaceguard Survey: Report of the NASA International Near-Earth-Object Detection Workshop, Jet Propulsion Lab/Cal Tech Report.

[4] Scotti. J.V., Rabinowitz, D.L., and Marsden, B.G., 1991, Near Miss Of The Earth By A Small Asteroid, Nature, Vol. 354, pp. 287-289.

[5] Tedeschi, W., 1994, Protecting Earth from Comet/Asteroid Impacts Through International Cooperation: Issues \& Current Status, Paper ISTS 94-n-16,19th International Symposium on Space Technology and Science, Yokohama, Japan.

[6] Canavan, G., Solem, J., and Rather, J., 1992, Proceedings of the Near-Earth-Object Interception Workshop, Los Alamos, New Mexico.

[7] Fujiwara, A., Kamimoto, G., and Tsukamoto, A., 1977, Destrurtion Of Basaltic Bodies By High-Velocity Impact, Icarus, Vol. 31, pp. 277-288.

[8] Kawakami, S., Mizutani, H., Takagi, Y, and Kumazawa, M., 1983, Impact Experiments on Ice, Journal of Geophysical Research, Vol. 88, No. B7, pp. 5806-5814.

[9] Anderson, C., 1987, An Overview of the Theory of Hydrocodes, Int. J. Impact Engng, Vol. 5, pp. 33-59. 
[10] Hartmann, W., 1978, Planet Formation: i.echanism of Early Growth, Icarus, Vol. 33, pp. 50-61.

[11] Arnold Engineering Development Center Test Facility Handbook (Thirteenth Edition), "Von Karman Gas Dynamics Facility," Vol. 3, May 1992.

[12] Wilbeck, J. and Young, R., 1992, Experience With Techniques For Characterizing Debris Generated During Hypervelocity Impact Testing, AIAA Paper 92-1586, AIAA Space Programs and Technologies Conference, Huntsville, AL.

[13] LeMaster, P, Zee, R., and Mount, A., 1992, Momentum Distribution In Debris Cloud During Hypervelocity Impact, AIAA Paper, AIAA Space Programs and Technologies Conference, Huntsville, AL.

[14] Halliday, D. and Resnick, R., Fundamentals of Physics, John Wiley \& Sons, Inc., 1974, pp. 160-161.

[15] Kirmo, J., 1994, Classifying And Modeling NEO Material Properties And Interactions, Hazards Due To Comets And Asteroids, U. Arizona Press.

[16] Greenberg, M. and Remo, J., 1994, A Current Working Model Of A Comet Nucleus And Implications For NEO Interactions, Hazards Due To Comets And Asteroids, U. Arizona Press.

[17] McGlaun, J., Thompson, S, and Elrick, M., 1990, CTH: A Three-Dimensional Shock Wave Physics Code, Int. J. Impact Engng, Vol. 10, 351-360. 
[18] Lee, R., Osher, J., Chau, H., Gerassimenko, M., Pomykal, G., and Speer, R., 1993, The Impact Of Flat, Thin Plates On Aluminum Targets in the $5-10 \mathrm{~km} / \mathrm{s}$ Velocity Range, Int. J. Impact Engng, Vol. 14, pp. 451-465.

[19] Stradling, G., Idzorek, G., Keaton, P., and Studebaker, J., 1990, Searching For Momentum Enhancement In Hypervelocity Impacts, Int. J. Impact Engng, Vol. 10, pp. 555-570.

[20] Tsou, P., 1990, Intact Capture of Hypervelocity Projectiles, Int. J. Impact Engng, Vol. 10, pp. 615-627.

[21] Hartmann, W., 1969, Terrestrial, Lunar, and Interplanetary Rock Fragmentation, Icarus, Vol. 10, pp. 201-213.

[22] Davis, D. and Ryan, E., 1990, On Collisional Disruption; Experimental Results and Scaling Laws, Icarus, Vol. 83, pp. 156-182. 
Table 1. Results of pendulum calibration tests using .22-caliber slugs.

\begin{tabular}{|c|c|c|c|c|c|c|c|}
\hline Shot \# & $\begin{array}{l}\text { Targo! } \\
\text { Mass (S! }\end{array}$ & $\begin{array}{c}\text { Slug } \\
\text { Mass (g) } \\
\end{array}$ & \begin{tabular}{|c|} 
Slug \\
Vol. $(\mathrm{m} / \mathrm{s})$ \\
\end{tabular} & \begin{tabular}{|c|} 
Slug Mom. \\
$(\mathrm{g} \mathrm{m} / \mathrm{s})$
\end{tabular} & $\begin{array}{l}\text { Mensured D iect. } \\
\text { Angle (deg) } \\
\end{array}$ & $\begin{array}{l}\text { Derlved Targot } \\
\text { Mom. }(\mathrm{g} \mathrm{m} / \mathrm{s})\end{array}$ & Error $(\%)$ \\
\hline 1 & 478.8 & 1.02 & 174. & 177.5 & 21 & 194.7 & +9.7 \\
\hline 2 & 478.8 & 1.92 & 148. & 204.1 & 29 & 267.5 & .5 .8 \\
\hline
\end{tabular}

Table 2. Matrix of impact test targets and shots.

\begin{tabular}{|c|c|c|c|c|c|c|c|}
\hline Shot \# & Date & $\begin{array}{c}\text { Impactor } \\
\text { Vel. (k/s) }\end{array}$ & Target & $\begin{array}{c}\text { Targel } \\
\text { Density }(g / c c)\end{array}$ & $\begin{array}{c}\text { Target } \\
\text { Mass (g) }\end{array}$ & $\begin{array}{c}\text { Energyl } \\
\text { Mass (J/g) }\end{array}$ & Impact Result \\
\hline 537 & $2-18-94$ & 8.13 & Scoraceous Rock & 1.0 & 80.1 & 7.9 & Small Crater \\
540 & $2-22-94$ & 8.23 & Mylar Sheel-Cal. Shot & 1.39 & 0.41 & - & Small Hole \\
541 & $2-22-94$ & 8.15 & AndesIne-Basalt Rock & 2.9 & 581.1 & 1.1 & Spall Fragments \\
543 & $2-24-94$ & 8.14 & Iron Meleorite & 7.7 & 477.6 & 1.3 & Small Crater \\
544 & $2-24-94$ & 8.04 & Comet Analog & 0.55 & 65.3 & 9.5 & Large Crater \\
545 & $2-25-94$ & 8.31 & Ice & 0.93 & 109.6 & 6.0 & Fragmentation \\
546 & $2-25-94$ & 8.17 & Aerogel & 0.224 & 24.7 & 25.9 & Medium Crater \\
548 & $2-28-94$ & 7.58 & Ollvine Bomb & 3.3 & 522.1 & 1.1 & Fragmentation \\
549 & $3-1-94$ & 7.69 & Compacted Snow & 0.56 & 66.5 & 8.5 & Large Crater \\
550 & $3.1-94$ & 8.41 & Iron-Rich Olivine Rock & 3.5 & 169.4 & 4.0 & Fragmentation \\
\hline
\end{tabular}

Table 3. Matrix of measured target deflection angles and impact test results.

\begin{tabular}{|c|c|c|c|c|c|c|}
\hline Shot \# & $\begin{array}{c}\text { Inil. Pend. } \\
\text { Mass (g) }\end{array}$ & $\begin{array}{c}\text { Final Pend. } \\
\text { Mass (g) }\end{array}$ & $\begin{array}{c}\text { Impactor } \\
\text { Mom. (g m/s) }\end{array}$ & $\begin{array}{c}\text { Measured Net Pend. } \\
\text { Deflect. Angle (deg) }\end{array}$ & $\begin{array}{c}\text { Derived Target } \\
\text { Mom. (g m/s) }\end{array}$ & $\begin{array}{c}\text { Momentum Deposition } \\
\text { Enhancemen Factor }\end{array}$ \\
\hline 537 & 563.4 & 560.9 & 156.9 & 58 & 606.7 & 3.87 \\
540 & 575 & 575 & 158.8 & 0 & 0 & 0 \\
541 & 618.9 & 545.9 & 157.3 & $58^{\circ}$ & 590.5 & $>3.75$ \\
543 & 514.8 & 513.2 & 157.1 & 18 & 179.12 & 1.14 \\
544 & 1003.1 & 960 & 155.2 & $50^{\circ}$ & 905.2 & $>5.83$ \\
545 & 1313.0 & 1205 & 160.8 & $48^{\circ}$ & 1093.6 & $>6.80$ \\
546 & 968.2 & 960 & 157.7 & 41 & 750.1 & 4.76 \\
548 & 923.5 & 484.9 & 146.3 & $47^{\circ}$ & 431.4 & $>2.94$ \\
549 & 2084.5 & 2034 & 148.4 & 37 & 1440 & 9.70 \\
550 & 743.5 & 627.2 & 162.3 & $58^{\circ}$ & 678.5 & $>4.18$ \\
\hline
\end{tabular}

NOTE:

- Pendulum deflection angle at maximum allowable value. The pendulum contacted the impact chamber wall. 


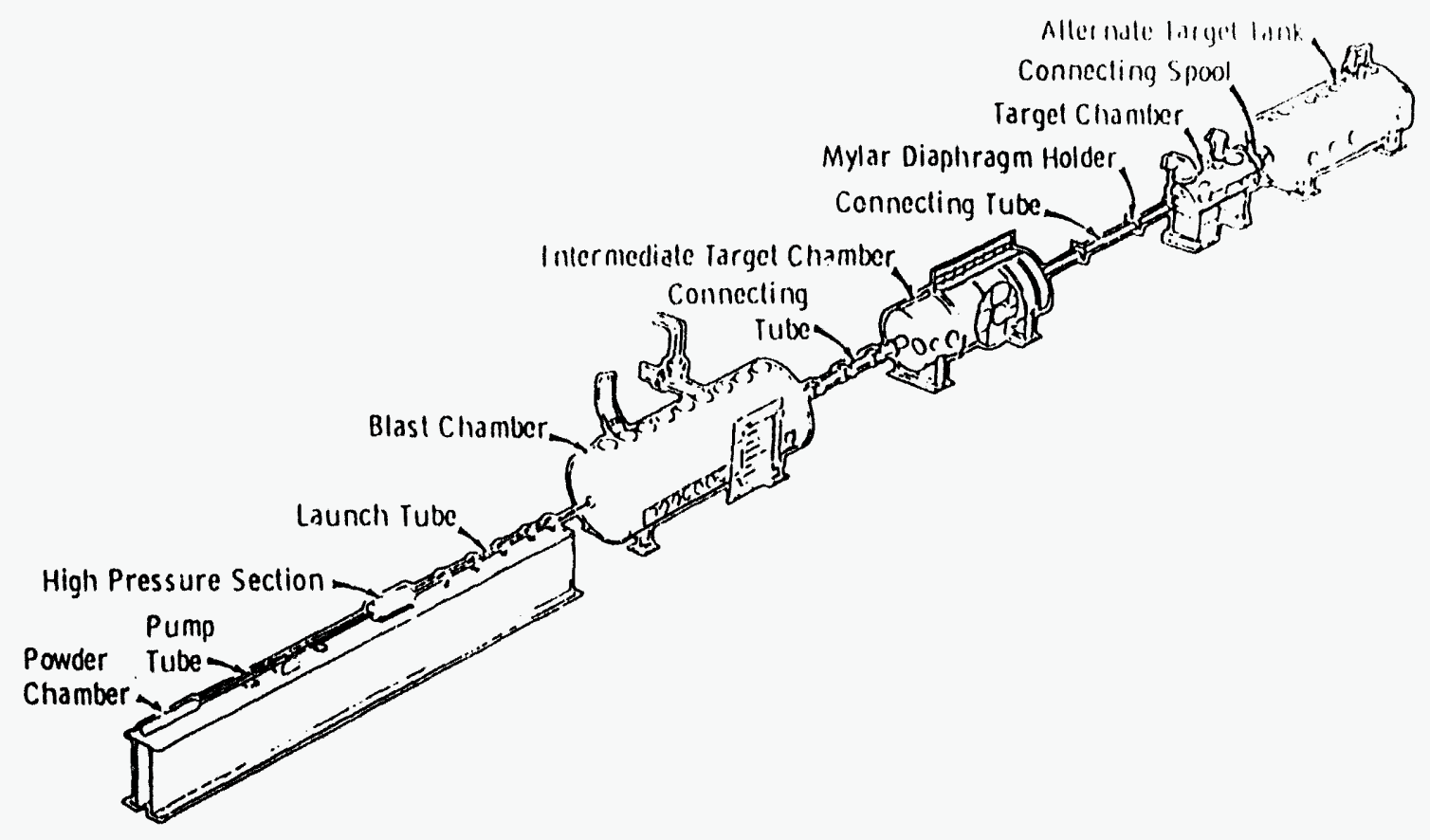

Figure 1. Air Force AEDC S1 range two-stage light-gas-gun facility layout.

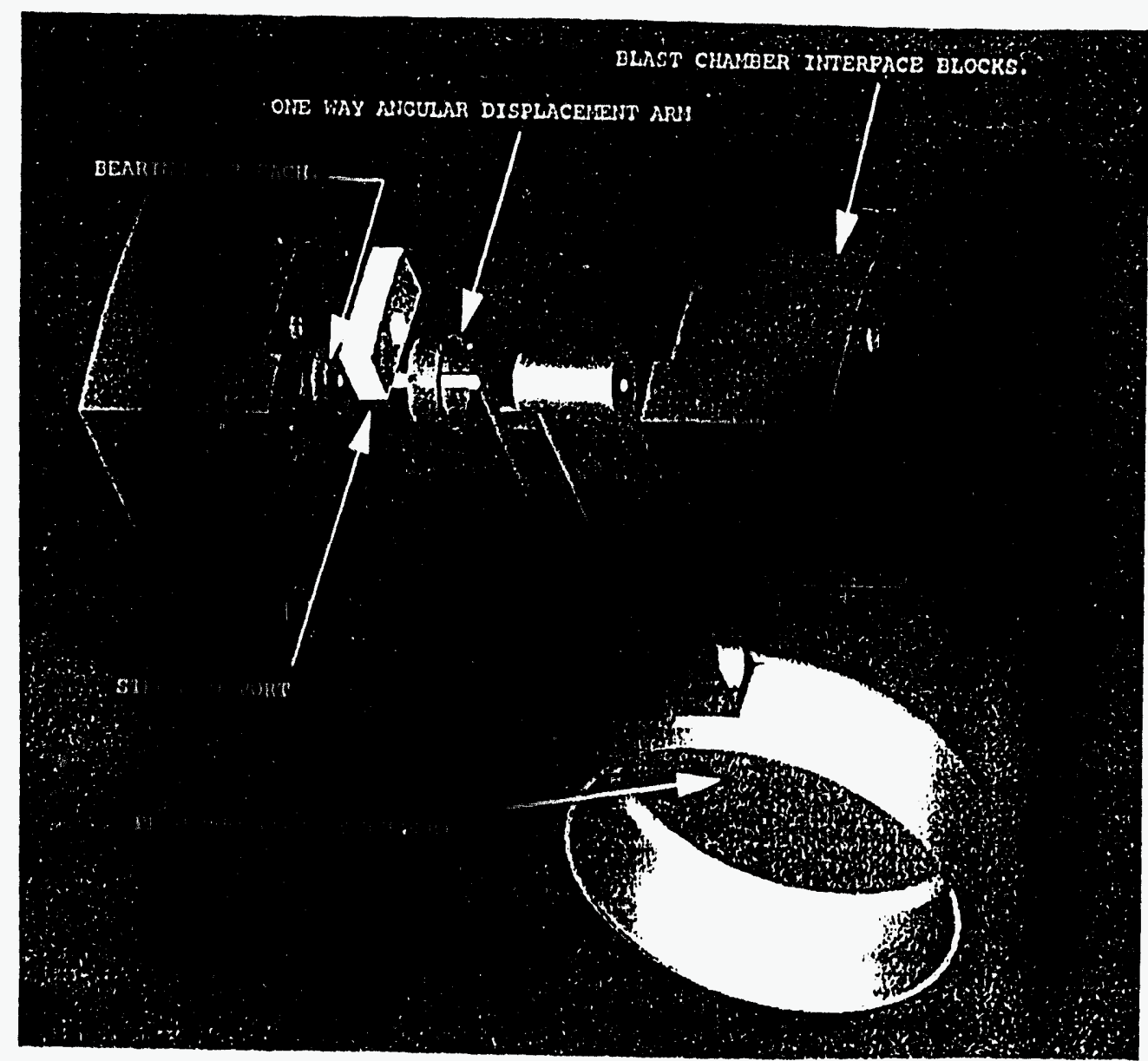

Figure 2. Drawing of the ballistic pendulum showing the component parts. 


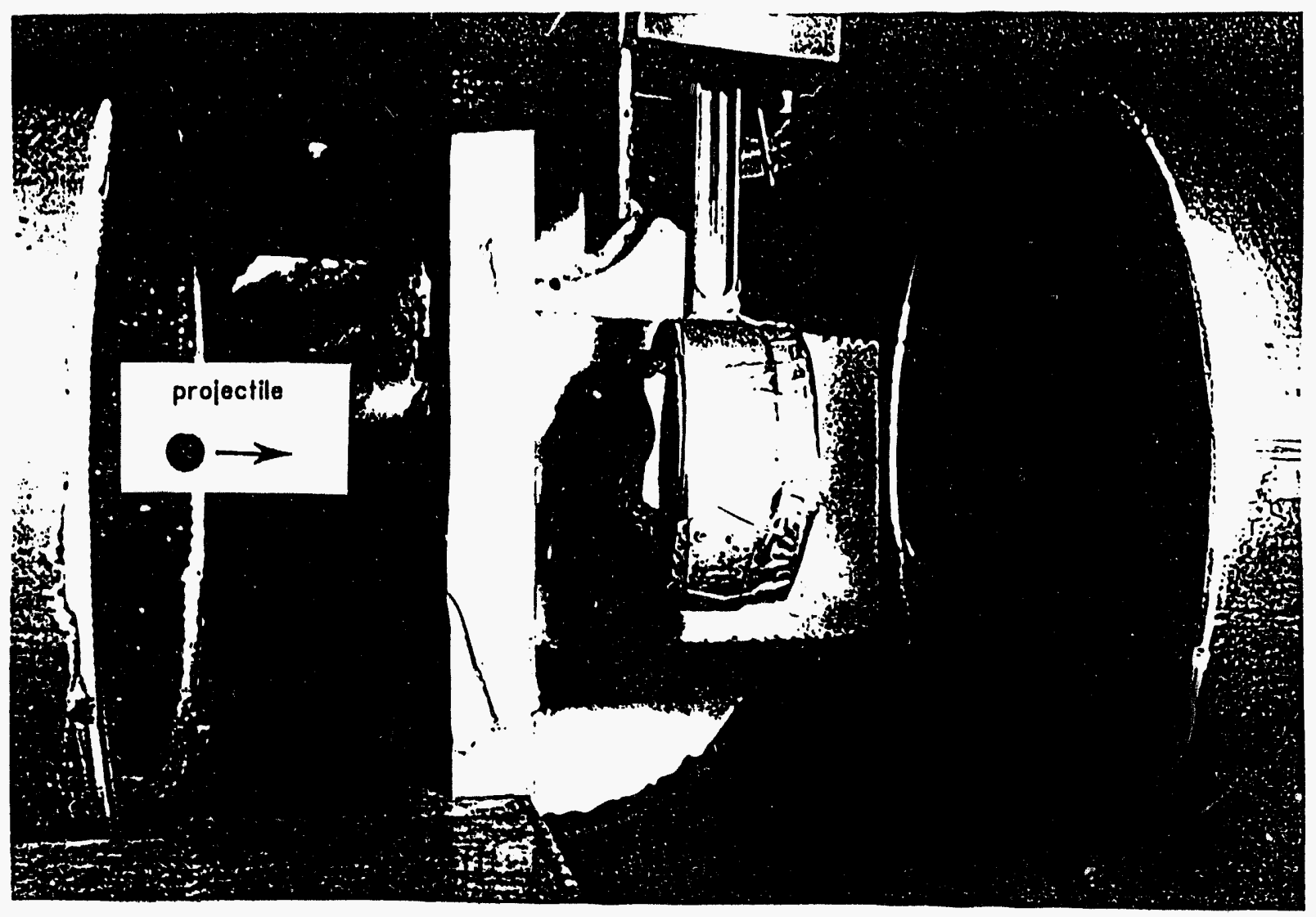

Figure 3. Photograph of the ballistic pendulum with the iron meteorite target mounted inside the impact chamber.

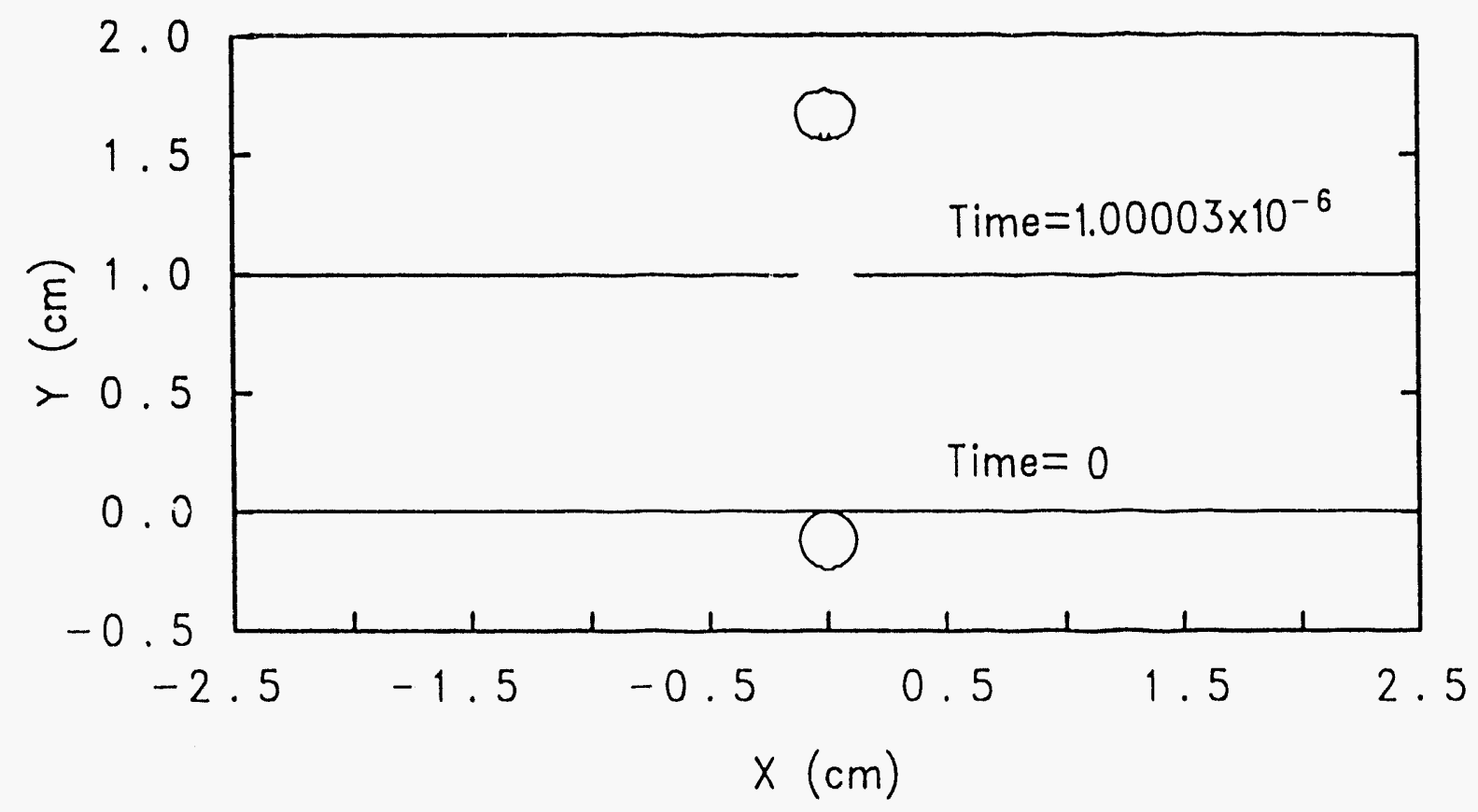

Figure 4. CTH calculation of the Aluminum projectile impacting the nylon blast shield. 
Time $=0 \mu$ sec



Time $=38.0 \mu \mathrm{sec}$



Time $=16.0 \mu \mathrm{sec}$

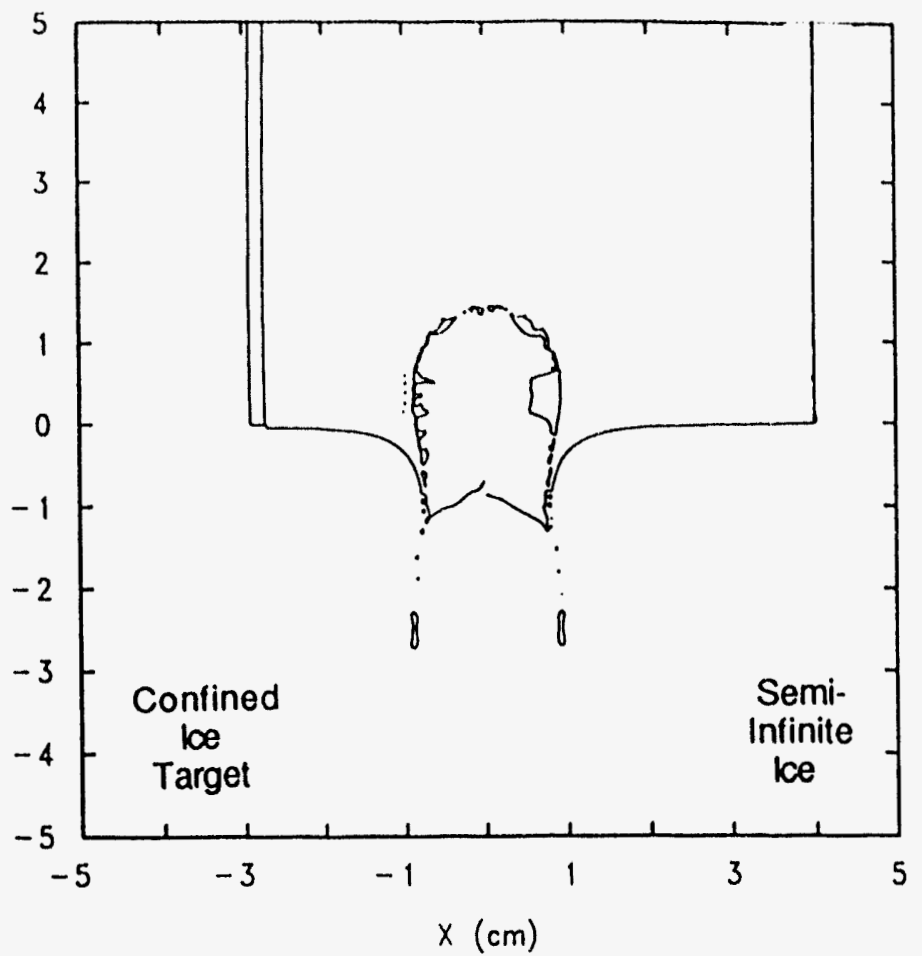

Time $=75.0 \mu \mathrm{sec}$

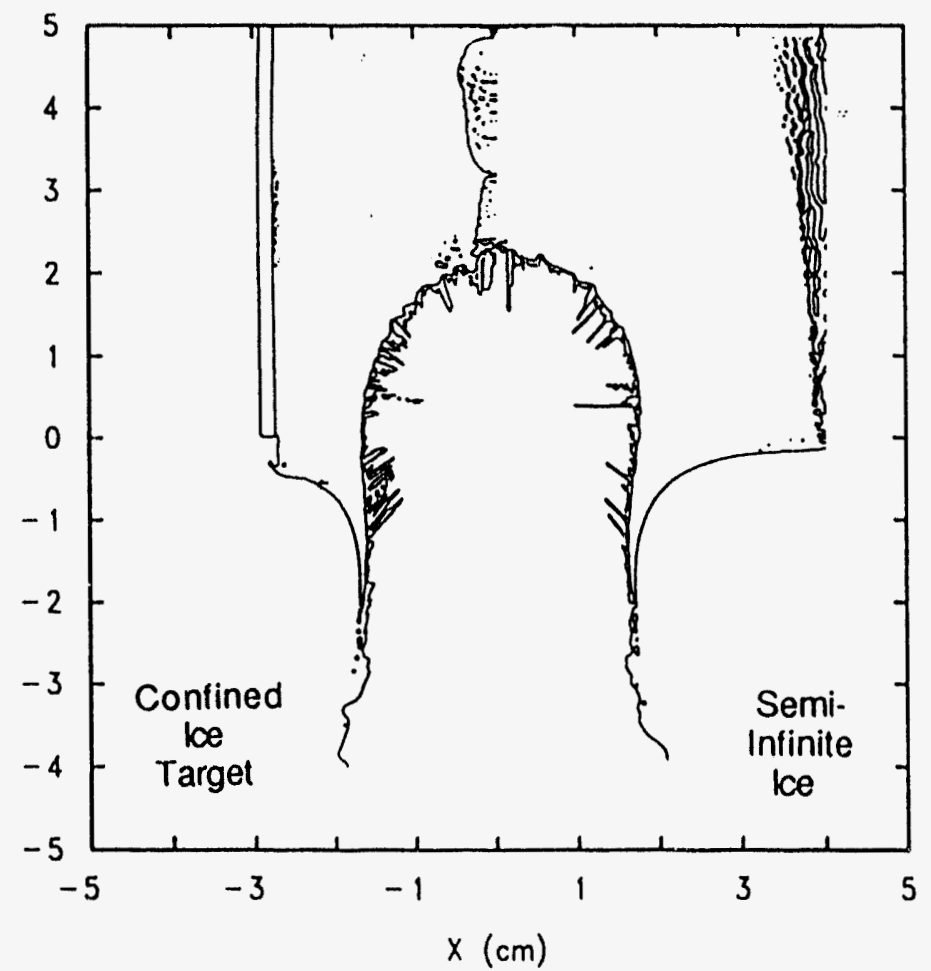

Figure 5. CTH-calculated Aluminum projectile impact into the confined ice (tested) target and a quasi--semi-infinite ice target at various times. 


\section{HEAVY COMET ANALOG}

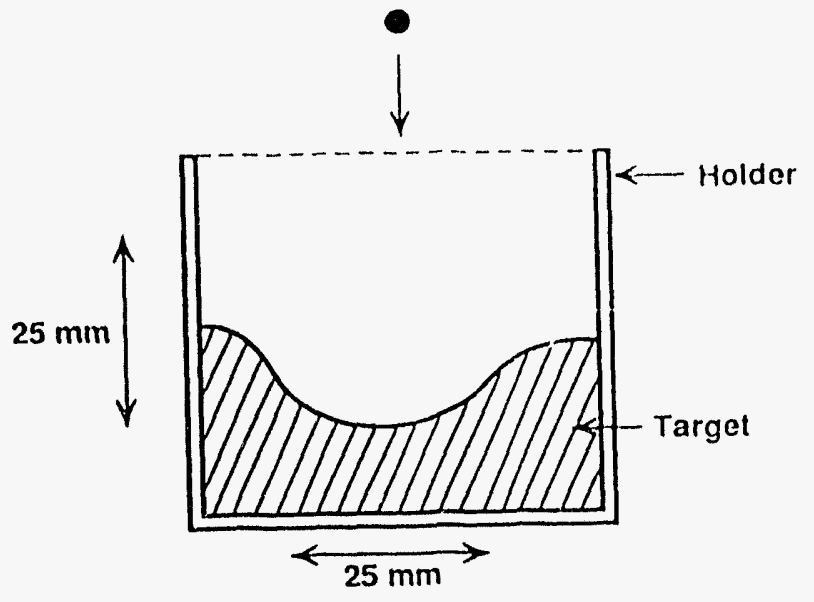

\section{COMPACTED SNOW}



Figure 6. Impact crater dimensions of the comet analog and compacted snow targets.

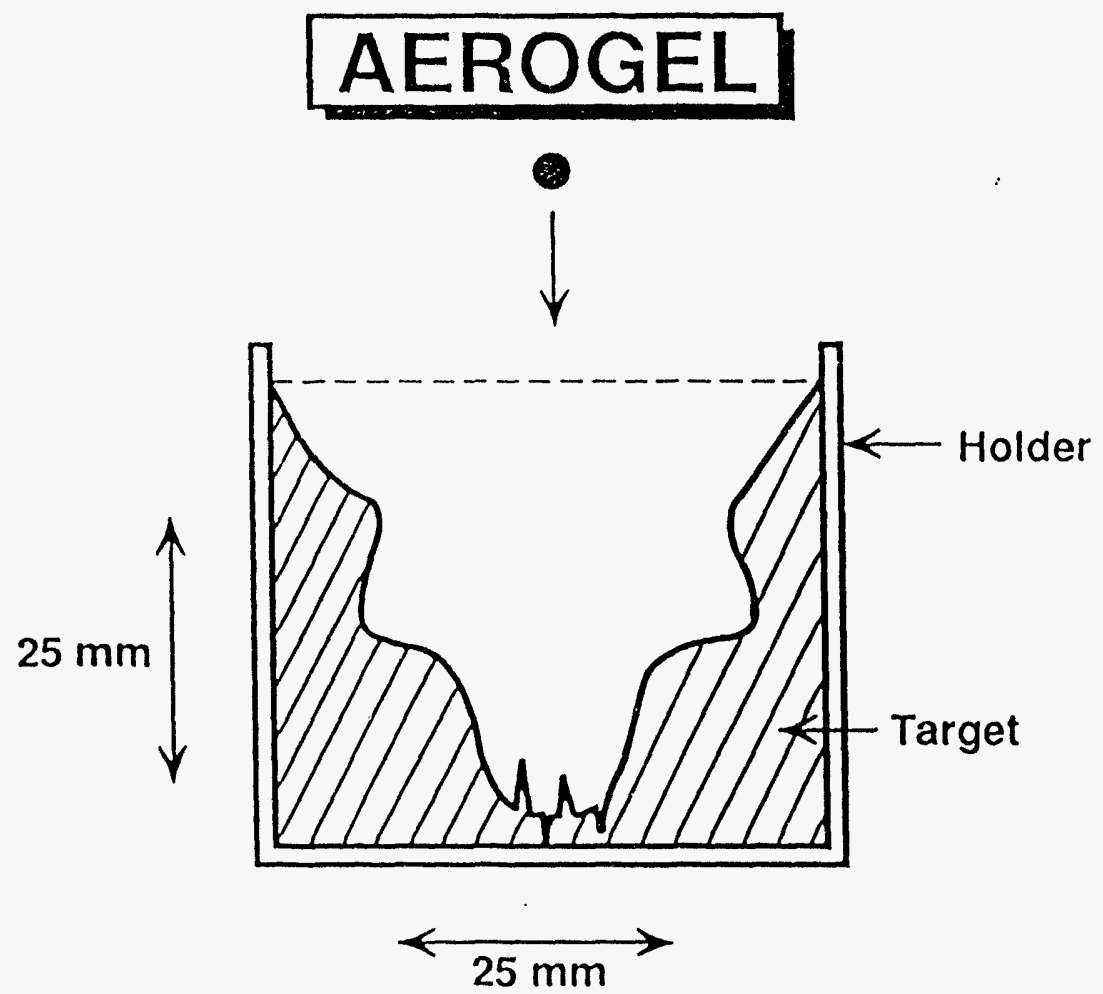

Figure 7. Impact crater dimensions of the low-density aerogel target. 


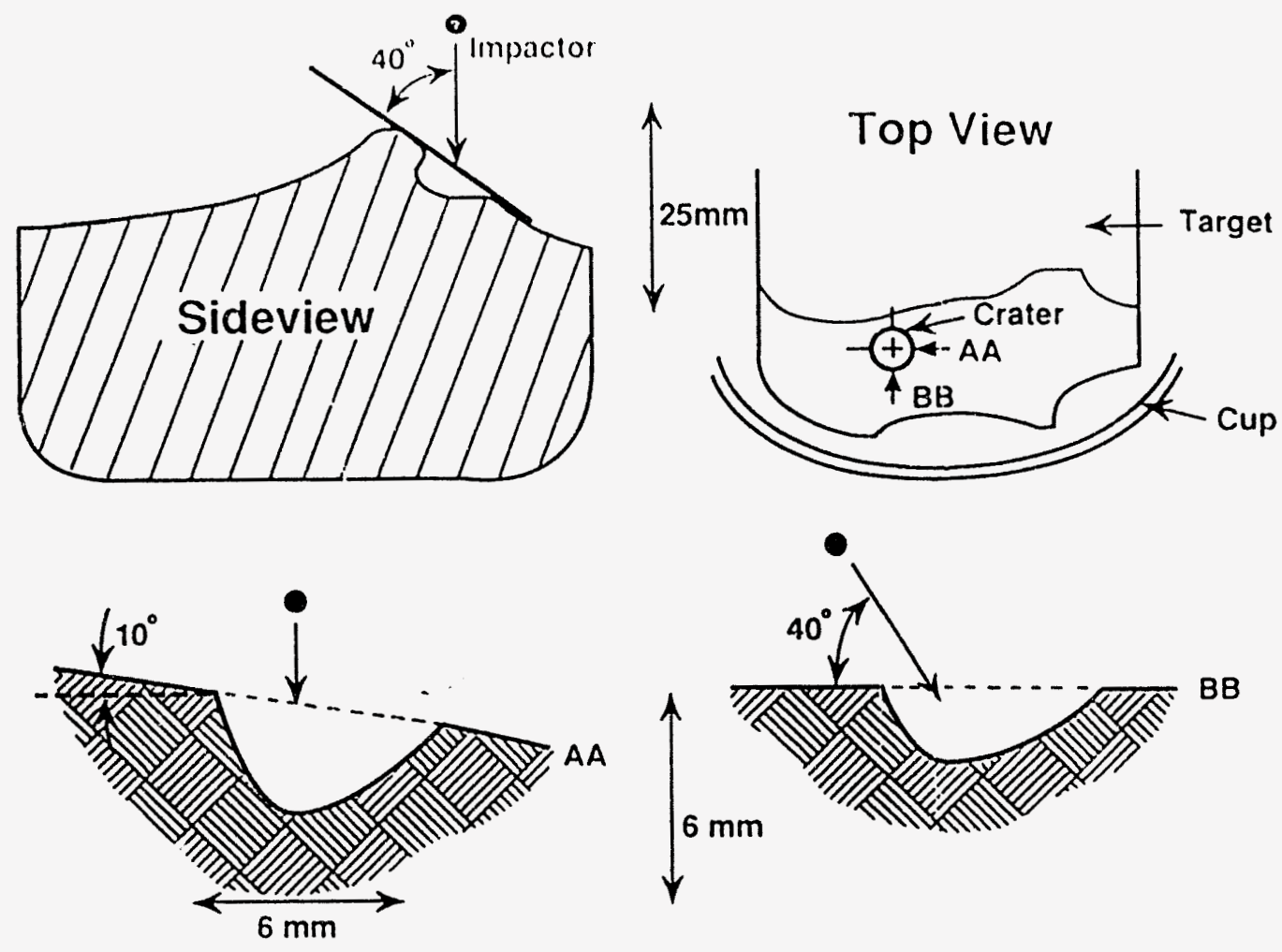

Figure 8. Impact crater dimensions of the iron meteorite target.

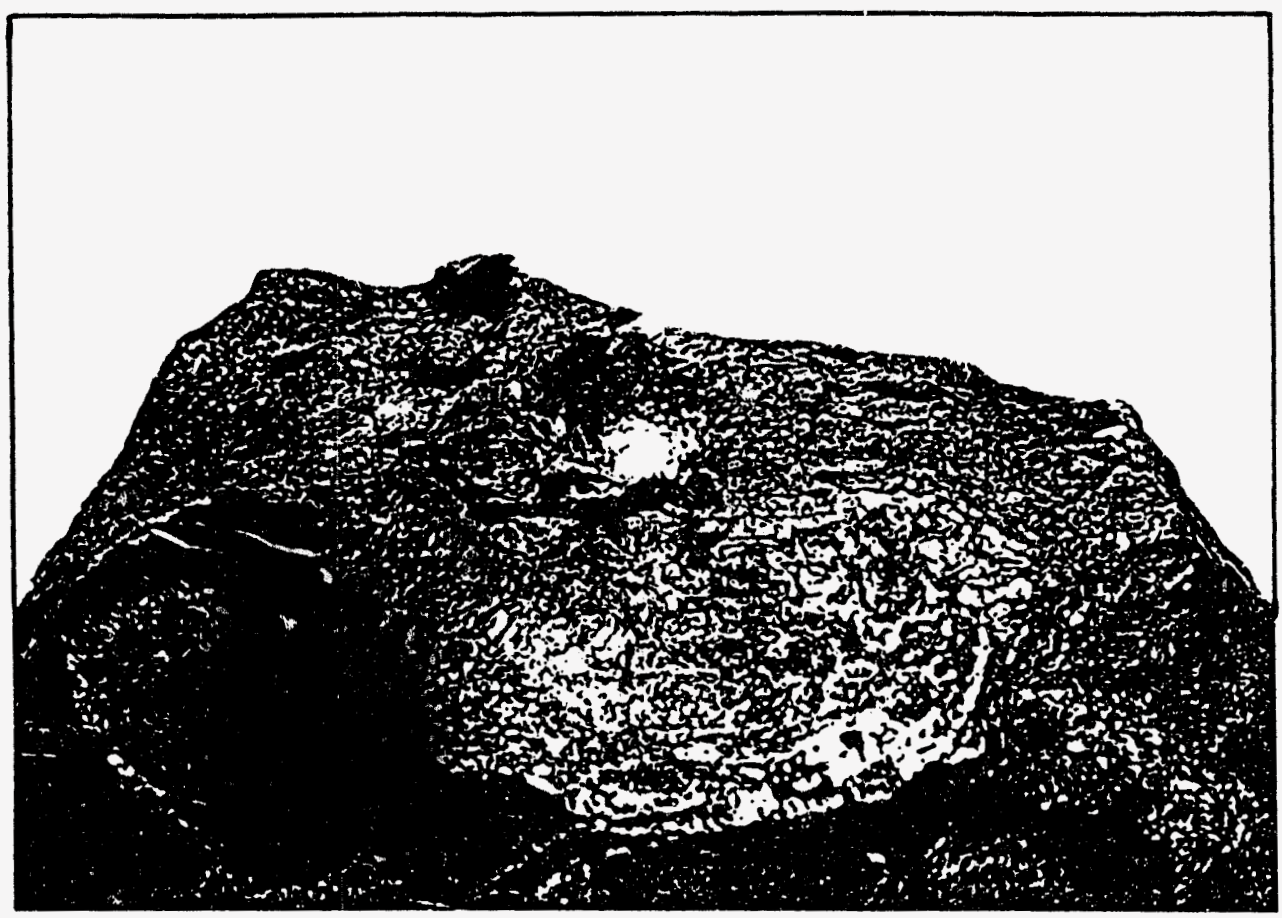

Figure 9. Photograph of the iron meteorite impact crater. 


\section{SCORACEOUS ROCK}
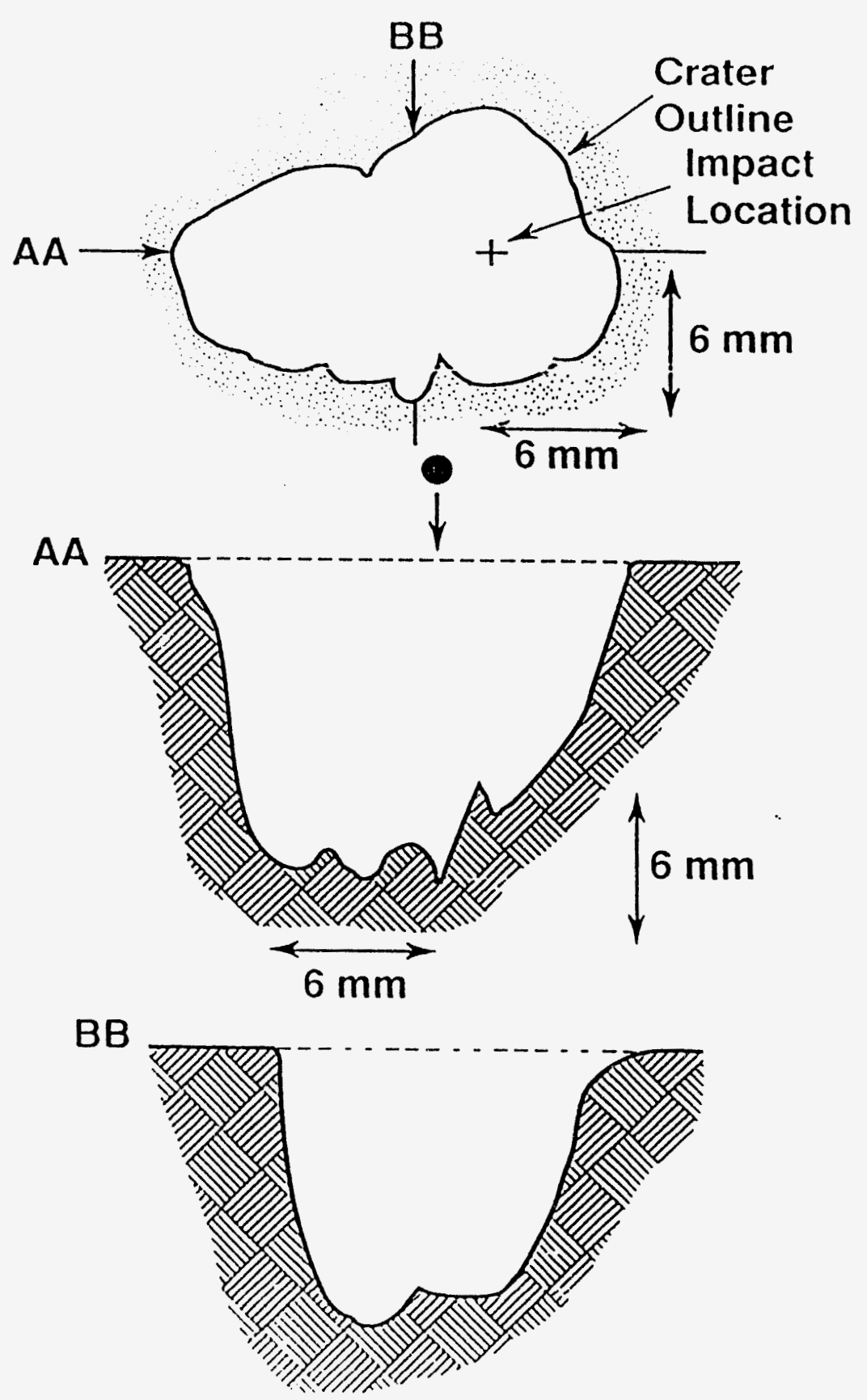

Figure 10. Impact crater dimensions of the scoraceous rock target. 


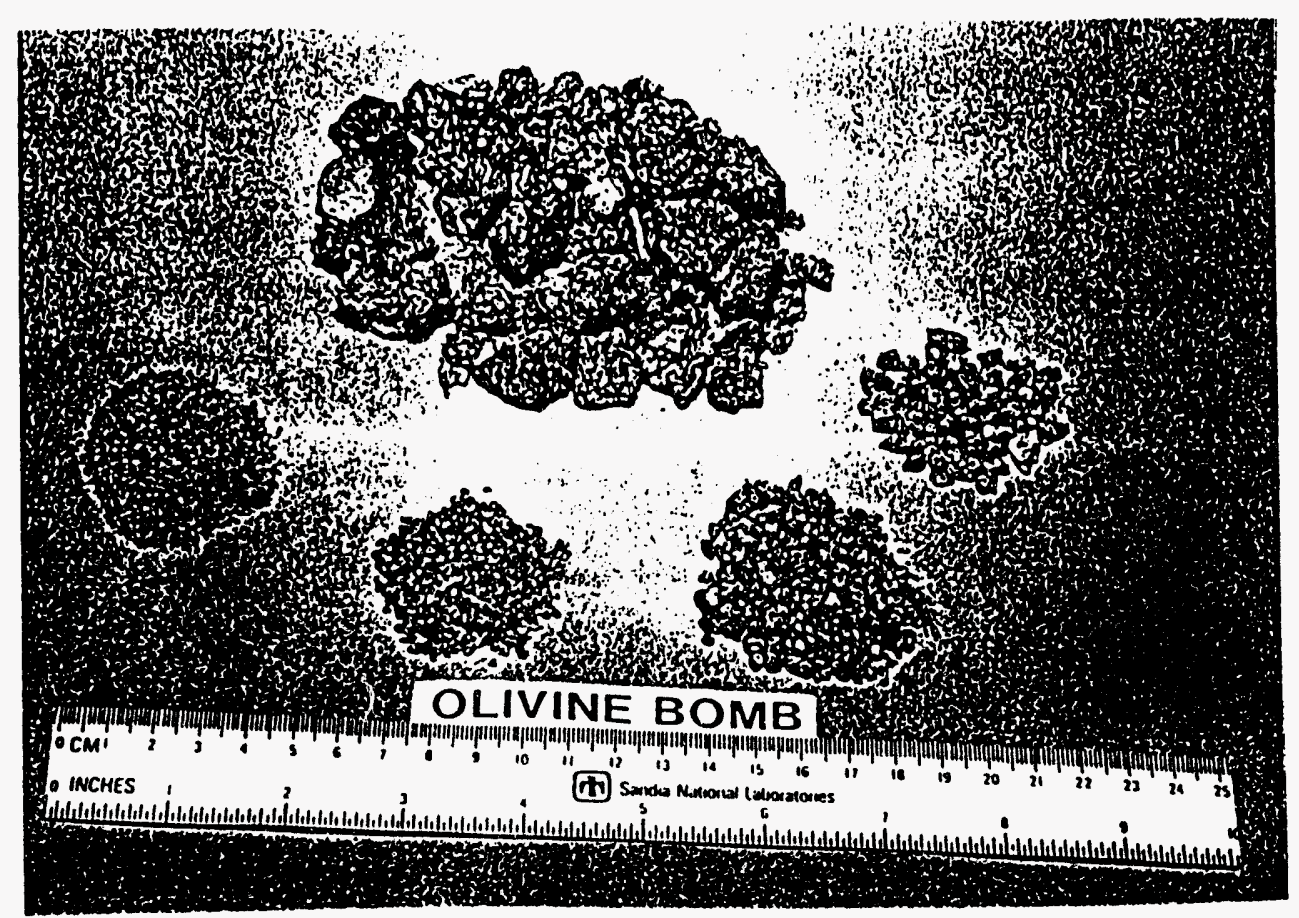

Figure 11. Recovered and sorted olivine-bomb target fragments.

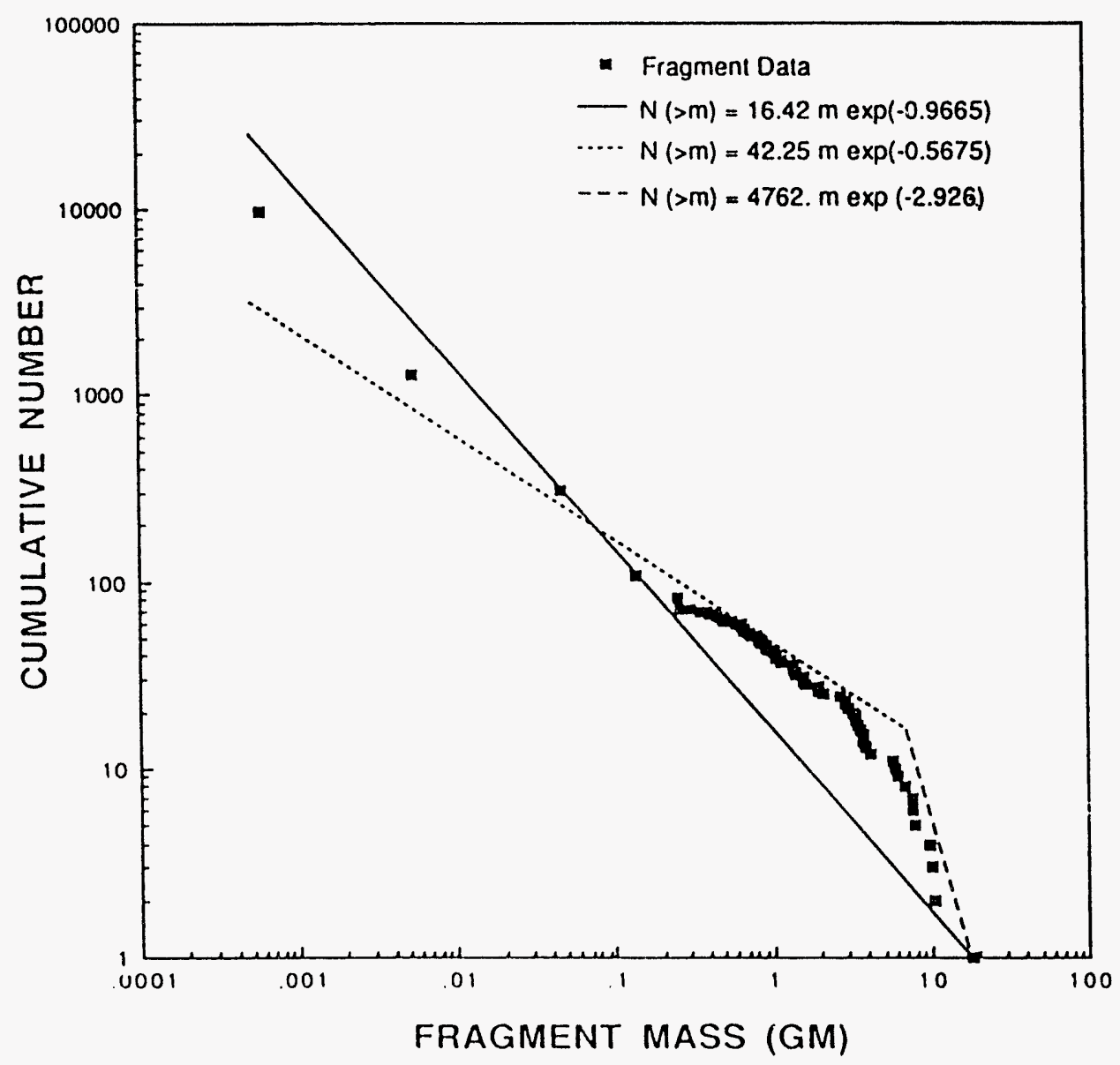

Figure 12. Olivine-bomb cumulative fragment distribution comparison with other distribution models $[22,23]$. 


